\title{
Engaging Community Stakeholders for School-Based Physical Activity Intervention Implicando a actores de la comunidad para la intervención en materia de actividad física desde la escuela
}

Jon Salsberg*, Soultana Macridis*, Enrique Garcia Bengoechea*, Ann C Macaulay*, Spencer Moore****

Members of the Kahnawake Schools Diabetes Prevention Project -School Travel Planning Committee

*McGill University, Montreal (Canada), **Kahnawake Schools Diabetes Prevention Project, Kahnawake (via Quebec, Canada), ***Queen’s University, Kingston, ON, (Canada)

\begin{abstract}
Sustainable school-based physical activity intervention is founded on the engaged participation of community individuals and organisational stakeholders who may facilitate or benefit from the intervention actions undertaken. Often in community-based research, intervention ideas are initiated by outside actors. Yet in order to develop and sustain programs successfully, community stakeholders must meaningfully be engaged, take ownership and assume leadership roles. To foster stakeholder engagement, health promotion specialists utilise strategies intended to create a sense of ownership among community stakeholders over the process. In practical terms this means that control over decision-making is actively placed into the hands of the end-users of the action. However, little is understood about how communities take control of the intervention process. Using social network analysis, we focus on a school travel planning project that was initiated from outside the community, and examine the co-evolution of community ownership, influence and decision-making within a multi-stakeholder network over the course of the project. Results show that despite the project's extra-community origins and its strong initial leadership by a non-community member, new community opinion-leaders emerged as central actors and knowledge leaders within the network over the course of the project's development. These interim results have implications for how community-academic research and programming partnerships are planned to develop and evaluate health promotion interventions.
\end{abstract}

Keywords: physical activity; school-based intervention; participatory research; community engagement; social network analysis.

Resumen. Las intervenciones sostenibles de actividad física en el entorno escolar se basan en la participación comprometida de las personas de la comunidad y las partes interesadas de la organización que pueden facilitar o beneficiarse de las acciones de intervención realizadas. A menudo en la investigación basada en la comunidad, ideas de intervención son iniciadas por agentes externos. Sin embargo, con el fin de desarrollar y mantener con éxito programas, las partes interesadas de la comunidad deben ser implicadas de manera significativa, tomar posesión y asumir roles de liderazgo. Para fomentar la participación de los interesados, los especialistas en promoción de la salud utilizan estrategias destinadas a crear un sentido de pertenencia entre los actores de la comunidad sobre el proceso. En términos prácticos, esto significa que el control sobre la toma de decisiones se coloca de forma activa en las manos de los usuarios finales de la acción. Sin embargo, poco se sabe acerca de cómo las comunidades toman el control del proceso de la intervención. Usando un análisis de redes sociales, nos centramos en un proyecto de planificación de transporte activo a la escuela que se inició desde fuera de la comunidad, y examinamos la evolución conjunta de la apropiación por parte de la comunidad, la influencia y la toma de decisiones dentro de una red de partes múltiples interesadas en el transcurso del proyecto. Los resultados muestran que a pesar de los orígenes extra-comunitarios del proyecto y su fuerte liderazgo inicial por un miembro que no era de la comunidad, los nuevos líderes de opinión de la comunidad surgieron como actores y líderes del conocimiento central dentro de la red a lo largo del desarrollo del proyecto. Estos resultados provisionales tienen implicaciones para la planificación de la investigación y la programación conjuntamente entre agentes comunitarios y universitarios afín de desarrollar y evaluar intervenciones para la promoción de la salud.

Palabras clave. actividad física; intervención basada en la escuela; investigación participativa; implicación comunitaria; análisis de redes sociales.

\section{Introduction}

For children to live healthy lifestyles, they need to have the opportunity to eat healthily and engage in adequate and appropriate physical activity (PA) (Doak, Visscher, Renders, \& Seidell, 2006). Family, community, and school have been identified as key environments where children form their opinions and habits regarding healthy living (Story, Kaphingst, \& French, 2006). Therefore, children’s health promotion efforts have focused on intervening in one or all of these areas (Doak, et al., 2006), and an ecological approach to health promotion suggests that sustainable interventions incorporate all three (Green \& Kreuter, 2005; Richard, Potvin, Kishchuk, Prlic, \& Green, 1996). Successful PA promotion must therefore take into account these ecological levels and their impact on the child's life when designing and implementing interventions (Green \& Kreuter, 2005).

At the organisational level, school-based health promotion intervention can have a significant impact on children's lifestyles (Story, et al., 2006; Veugelers \& Fitzgerald, 2005). Yet, for school-based PA to be successful, it also needs to account for the impact of the community environment on the intervention's ability to change the opinions and behaviours of children (Bisset, Daniel, \& Potvin, 2009). Schools as organisations function within an environment of other communitybased organisations concerned with the health and social needs of children. Therefore, to improve children's health successfully, these organisations should be engaged and collaborate to avoid duplicated or conflicting policies and services, and to leverage each organisation's

Fecha recepción: 30-09-14- Fecha envío revisores: 30-09-14- Fecha de aceptación: 15-11-14 Jon Salsberg

jon.salsberg@mcgill.ca expertise and resources in creating health promotion interventions (Luke \& Harris, 2007b)

In community-based intervention research, such as school-based PA planning, community stakeholders may collaborate with outside academic researchers who are often the originators of the intervention or research idea (Hogan et al., 2014; A. C. Macaulay et al., 1999). However, successful, sustainable intervention outcomes are founded on community stakeholders being engaged and ultimately taking ownership over the development and deployment of the interventions (CacariStone, Wallerstein, Garcia, \& Minkler, 2014; Green \& Kreuter, 2005; Hogan, et al., 2014). Meaningful engagement with other organisations can lead to greater community input into school-based PA intervention planning (Valente, Coronges, Stevens, \& Cousineau, 2008; Valente, Fujimoto, Palmer, \& Tanjasiri, 2010) and therefore greater community ownership and self-determination over the intervention process.

For community-based organisations to be meaningfully engaged, collaborate successfully and thus build ownership and self-determination, they need to establish and maintain working linkages between them (Provan, Nakama, Veazie, Teufel-Shone, \& Huddleston, 2003). These linkages foster the flow of knowledge and information needed to intervene successfully in areas of common interest (Provan, et al., 2003; Valente, 2010), such as children's PA promotion. Examining collaboration and knowledge-sharing among organisations engaged in community-based PA promotion provides an understanding of how interventions are planned and implemented, participants are reached and recruited, and public health goals are achieved. (Kegler, Rigler, \& Ravani, 2010; Luke \& Harris, 2007a; Provan, et al., 2003). The study of these linkages, the overall structures that they create, and the impact that they may have on the behaviour of individual actors, are the focus of social network analysis. 
To understand how engagement, community ownership and selfdetermination evolve, this study adopts a social network approach to examine the knowledge-leadership and decision-making roles stakeholders take throughout the development of a school-based PA intervention project. Control over knowledge flow is associated with opinion leadership and thus can serve as a useful measure of influence within a network (Eccles \& Foy, 2011; Valente, 2010).

What does the evolution of a stakeholder network look like when it is initiated by a non-community champion, then grows into a functioning network once a coalition of community organisations are engaged and collaborating to develop the program?

Using an existing school-based PAintervention project (the KSDPP School Travel Planning Project), this study will map the evolution of a researcher-stakeholder collaboration to determine its structure from project conception by the non-community champion (T1), to intervention deployment within the community (T2). Social network analysis is used to map the network and analyse changes in its structure, including the paths of influence and knowledge sharing.

\section{Social Network Analysis}

A social network can be defined as connections among people, organisations or other social actors (Valente, 2010). Although the individual attributes of these actors can determine their social network, network analysis focuses rather on their relationships and how these affect their behaviour. These relationships - or network links or ties are the connections among, within and between the actors and the goal of network analysis is to understand how a network can influence and constrain the behaviour of its members (Valente, 2010). Social network studies tend to take either a whole network design, looking at the sum of component actors as members of a bounded social collective; or an egocentric design, examining networks from the perspective of the actors within them (Marsden, 2005). Studying networks of individuals has led to greater understanding of how, among others, diseases, ideas and opinions spread; how people access social support; and who or what influences their health behaviour (Turcot et al., 2009). Network analysis has examined how health service organisations collaborate to share information, plan and deliver services (Doak, et al., 2006; Potvin \& Lamarre, 2009; Story, et al., 2006; Turcot, et al., 2009). Within community-based participatory health research, it has been used to evaluate how community health workers share and use evidence (Campbell et al., 2014; Valente, et al., 2010), to examine interpersonal support networks (Fuller, Hermeston, Passey, Fallon, \& Muyambi, 2012; Langhout, Collins, \& Ellison, 2013; Leonard, Horsfall, \& Noonan, 2014), and to examine issues of access and equity (Luque et al., 2011; Pauly, MacDonald, Hancock, Martin, \& Perkin, 2013; Ramanadhan et al., 2012). For children's PA, social network analysis has been used to examine peer influence on intervention effects (Shin et al., 2014). Fuller, et al. (2012) showed that social network analysis could serve as an effective and culturally-acceptable approach within Aboriginal communities. Within that study, community members considered that the network analysis had accurately described the links between workers related to the exchange of clinical and cultural information, team care relationships, involvement in service management and planning and involvement in policy development (Fuller, et al., 2012).

Within social network analysis, much attention has been paid to identifying and understanding the roles of central actors. Centrality can be defined as the extent to which an actor occupies a prestigious or critical position in thenetwork (Valente, 2010). This position is associated with opinion leadership and is often seen to accord status, control over resources, and influence over the opinions and behaviours of others. Centrality has been seen as having the strongest direct effect on organisations' influence within their networks, such as among community-based service organisations (Galaskiewicz, 1979); and has been the frequent target of network intervention studies that aim to optimise a network's ability to share information or spread desirable behaviours or practices (Gest, Osgood, Feinberg, Bierman, \& Moody, 2011; Poole, 2008; Valente, 2010). There are various measures of centrality; of these measures in-degree measures the number of times an actor is named by others in the network. For example, in-degree centrality can measure how frequently a community-member is named by others as someone they turn to for information or help. In both intervention planning and within the interventions themselves, it is important for success that people with high in-degree centrality are recruited early on as champions, as they are role models to whom others turn for leadership, and therefore have potential to increase the adoption and sustainability of the intervention (Rogers, 2003). Indegree centrality is furthermore the most robust of all the centrality measures when working with missing or incomplete data (Costenbader \& Valente, 2003).

Besides examining central actors, social network analysis can also look at how centralised a network is overall. Centralisation is the extent to which network links are focused on one or few actors (Valente, 2010). One key implication of the centralisation of a network is on the spread of knowledge, ideas, opinions and behaviour. Centralised networks have the potential to increase or decrease the pace of uptake of an innovation or policy depending on the commitment of its central actors. Central actors are gatekeepers, possessing disproportionate amount of influence over the network, therefore opinion leaders are much more critical to the success of community-based initiatives in centralised networks than in decentralised ones (Valente, 2010).

\section{Setting and Context}

This study is part of the Kahnawake Schools Diabetes Prevention Project (KSDPP), a 21-year old community-owned participatory research partnership between the Kanien'kehá:ka (Mohawk) community of Kahnawake and academic researchers from McGill University, Queen's University and Universitéde Montréal. Kahnawake First Nation is located $12 \mathrm{kms}$ from downtown Montreal, Quebec, on the south shore of the St. Lawrence River. This community of approximately 8000 (2011 est. enrolled, on reserve) enjoys a high a level of socioeconomic development while valuing and maintaining the Kanien'kéha language and traditional institutions of culture and governance. The community has, since the late 1960s and early 1970s respectively, maintained local control over both its health and education systems; and thus operates its own school board, full-service inpatient hospital, and wide range of health and social services. Since 1994, KSDPP had developed and delivered community intervention programming to increase healthy behaviours and reduce incidence and prevalence of type 2 diabetes. KSDPP has continuously evaluated its efforts along a spectrum of process and outcome measures ('A. C.' Macaulay et al., 1997; Macaulay et al., 2007; Paradis et al., 2005); has evaluated its participatory partnership (Cargo, Delormier, Levesque, McComber, \& Macaulay, 2011; MCargo et al., 2003); has disseminated its prevention planning model to over 30 Indigenous communities across Canada (KSDPP, 2014); and has served as a platform for numerous studies on health promotion, primary prevention of diabetes, nutrition, PA, healthy school policy planning, and the participatory process (see http://pram.mcgill.ca/ksdpp_pubs.php for the full range of published KSDPP research). KSDPP is governed exclusively by its Community Advisory Board (CAB) comprised of community volunteers representing many sector of Kahnawake. CAB oversees and approves all intervention and research planning, including ethical review of protocols and approval of dissemination. CAB serves as the primary site of engagement between community and researchers; it is where community voices inform the research agenda, and where community minds interpret its results. In 2010, KSDPP and its CAB received the CIHR Partnership Award, recognising excellence in researcher/ knowledge-user engagement.

In 2005, KSDPP began working with community members and organisations to develop and implement school-based wellness policies in support of children's healthy active living. The first phase of work addressed the nutrition component of the wellness policy for two community elementary schools overseen by the Kahnawake Education Centre, the local school board. The combined population of these schools 
is approximately 410 . The nutrition policy was implemented in the 2009-2010 school year. In response to a community-initiated call to complete a balanced wellness policy, in 2011 KSDPP researchers along with their university-based partners received a Canadian federal research grant to support the development and implementation of the PA policy component. This PApolicy development began with a baseline evaluation that produced data about current PA levels of children, children's preferences, perceived barriers and facilitators to PA, current school practices and programs, stakeholder opinions on potential policy content and more. These data, together with existing evidence and policy guidelines, were used by KSDPP along with the coalition of community stakeholders and university researchers, to develop a PA policy comprised of key target areas within schools where opportunities exist for PApromotion. Details of the PAPolicy project can be found elsewhere (Hogan, et al., 2014).

\section{The Intervention}

This current study focuses on the PA Policy's identified target of school active transportation, the ability for children to be able to use physically active means of getting to and from school, such as walking or biking. (Hogan, et al., 2014; Macridis et al., 2015). For this, the School Travel Planning (STP) project was developed using the Active \& Safe Routes to School -School Travel Planning process, as recommended by Active Healthy Kids Canada (Active-Healthy-Kids-Canada, 2014). The STP process entails 5 collaborative phases: Setup; Data Collection \& Problem Identification; Action Planning; Implementation; and Evaluation and Maintenance (Green-Communities Canada, 2012). Phases 1-3 occurred between January 2013 and July 2014. For the setup phase, school and broader community members and organisations were invited to a community presentation in December 2012 to learn about the STP-Project. It was here that community members signedup for the project. These individuals were later contacted to form the STP-Committee and commenced meetings in January 2013. The STPCommittee comprised of 11 community, school and researcher stakeholders including: two principals, a classroom teacher, a physical education teacher, a bus transportation manager, a community protection officer, two KSDPP intervention staff, one KSDPP Community Advisory Board member, with one doctoral student in kinesiology and physical education (author $\mathrm{SM}$ ), her $\mathrm{PhD}$ academic supervisor (author $\mathrm{EBG}$ ) and $\mathrm{PhD}$ committee member (ACM) from the KSDPP research team. The doctoral student introduced the STP project as her dissertation project (Macridis, 2015) to KSDPP and the community and, after acceptance from both, then served as the project's PI/champion and facilitator throughout its development.

The PI/champion began by recommending that the committee explore adapting the Active \& Safe Routes to School (ASRTS) framework, which the STP committee agreed was culturally appropriate for the community. ASRTS provides samples of step-by-step procedures, timelines, and data collection activity samples to inform school AT program planning. From January 2013 - August 2014, PI/champion and committee members met monthly and successfully defined a terms of reference document and project timeline goals. Through a collaborative process, they also refined data collection activities to be culturally appropriate, as well as relevant for future program planning. Initially, five data collection activities were agreed upon, however, through reflection of early findings, a sixth activity was co-developed based on a knowledge gap. Activities included: i) school profile form; ii) student in-class travel survey; iii) parent survey; iv) school walkability checklist; v) pedestrian-traffic observations; and vi) in-class mapping activities.

The data collection and analysis process occurred between August 2013 and May 2014, with some activities occurring at key seasonal dates; a decision made by the STP-Committee. Committee members were involved in one or more data activities as data collectors and/or organizers, which allowed for first-hand observations and experiences. While few were involved in analyses which was completed by the PI/ champion, all had an opportunity to interpret the results, which allowed for enrichment of results and immediate dissemination of findings to the organisations to which the committee-members belonged. More specifically, through discussions of key findings, STP-Committee members were able to better define what needed to be done to support school AT programming in their schools and community. This aligned with STP-Process 3, action planning, which took place between March and August 2014. Through action planning meetings, members determined key goals and actions/initiatives for implementation in the 2014-15 school year. Examples of goals based on findings included: to increase the number of children using AT to and from school; improve traffic and pedestrian safety; increase law enforcement during peak school hours; and increase law enforcement presence.

Using the ASRTS STP-Action Planning template, members further identified key actions/initiatives under six key objective areas in support of their goals. Key objectives included: i) improve the safety of children on the active school journey; ii) raise awareness of the environmental and health benefits of AT; iii) encourage more students to walk to school; iv) encourage more students to walk from school to after-school programs; v) facilitate safe bicycling to and from school; and vi) monitor the effectiveness of initiatives and revise School Travel Plan (GreenCommunities Canada, 2012). For example, to encourage more students to walk to school, committee members determined that a Walking School Bus program, an internationally used program (Buliung, Faulkner, Beesley, \& Kennedy, 2011; Chillon, Evenson, Vaughn, \& Ward, 2011), would be appropriate. Such programs are tailored towards students living within a school's walkable distance policy. However, the STPCommittee wanted to be inclusive, and tailored their program to be a Walking School Bus drop-off program, where all students, whether bussed or not, could meet at specific location to walk to school under adult supervision. As part of raising awareness and to encourage student to use AT, various promotional and educational activities were developed, such flyers/brochures to students and parents, contests, and pedestrian, traffic, and cycling safety workshops. Committee members assigned themselves to one or more actions/initiatives based on their organization, knowledge and expertise. Finally, the PI/champion provided support for various actions/initiatives up until and including their first Walking School Bus drop-off program during the first week of October 2014. At this time, as per initial agreement with the STP committee, the PI/ champion had completed data collection for her thesis and left for other employment. This left committee members to carry the project forward into implementation and evaluation and maintenance phases.

\section{Methods}

This study uses social network analysis (SNA). Sample: This is a sociometric study of the community/academic stakeholder committee for the STP project. This closed-membership committee is a whole network of community stakeholders representing the various interests in the STP project, including school administrators and teachers, parents, public safety and public works officials, along with KSDPP intervention facilitators and academic researchers from McGill University. The network consists of 13 actors, representing the 11 members of the STP-Committee plus two others identified as KSDPP individuals who played a significant role at the time the idea was initially being discussed. Each of the actors in this network was administered a questionnaire covering two occasions in the life of the project (project initiation and completion). Project initiation (T1) was in January 2013, and completion of project planning (T2) was July 2014.

Network Questionnaire: The network questionnaire consisted of a fixed list of the 13 members of the STP committee with a box next to each name in which they could write their rank number. The retrospective item for baseline network relationships (T1) read: «Looking back to the beginning of the project, please rank the committee members in order of who you would turn to for information relating to the STP project at that time.» Participants were instructed to rank only those actors with whom they actually spoke to about the project at that time, and to leave the box blank if they had not spoken with the actor. At project completion (T2), participants were asked: «From the provided list of 
names, please rank the committee members in the order of who you would turn to for information relating to the STP project.» At both times, the respondents were invited to include themselves in their rankings.

Measures: Using UCINET 6 SNA software, in-degree centrality and network centralisation were calculated. In-degree centrality is a binary measure (nominated or not nominated) that does not include rank-order of nomination in its calculation. In other words, if a respondent nominates the same alters (other members) at $\mathrm{T} 1$ and $\mathrm{T} 2$, but their ordering of alters changes over time to reflect a change in who they go to for information, these changes will not be reflected in the centrality scores. If all nominations are retained, then the resulting network maps for T1 and T2 will not demonstrate any marked change. However, because rank order can stand as a proxy for tie strength (Valente, 2010) we retained only the top 5 nominations from each respondent, representing their 5 strongest nominations; and thus producing network maps that are demonstrably different for each sample time. Freeman's in-degree centrality (asymmetric model) was calculated for eachnetwork member, including diagonal values (because ego [oneself] valuing ego as information source is significant). Response ranks were reverse transposed, so that ranked $1^{\text {st }}$ becomes the highest value for the calculation of tie strength. Network Centralisation was calculated for each sample time. Centralisation is the extent to which a network's ties are focussed on one or a set of actors (Valente, 2010). In a highly centralised network, one or a few actors hold positions of power and control, while decentralised networks have defused power and control structures. Network centralisation is related to individual centrality in that it is calculated on the difference between the maximum individual centrality score and all the others within the same network.

\section{Results}

Table 1 reports network centralization scores at baseline and program maturation. Although centralisation increased at T2, comparing network densities (the number of actual ties as a proportion of the total possible number of ties) across times (paired t-test) showed no significant change from T1 to T2; so network density did not significantly increase or decrease the stakeholders' ability to collaborate. Individual centrality scores for T1 and T2 are reported in Tables 2. Network maps describing the relationships between actors and the strength of their ties at $\mathrm{T} 1$ and T2 are shown in Figures 1 and 2.

At T1, the network was highly centralized around one individual, the PI/project champion, who was nominated and ranked first by every other alter (in-degree centrality $[\mathrm{inDC}]=36.00$ ). By T2, that same individual still dominated the information network (in-degree centrality increasing to 61.00 by virtue of larger size network at T2 with all members nominating this ego). However, the remainder of the network had nominated other knowledge leaders, with significant increases in

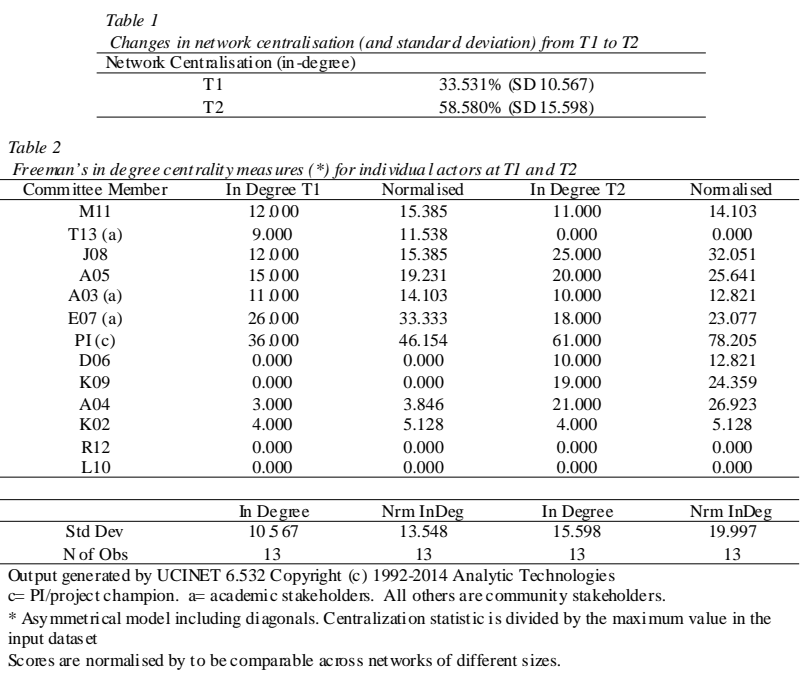
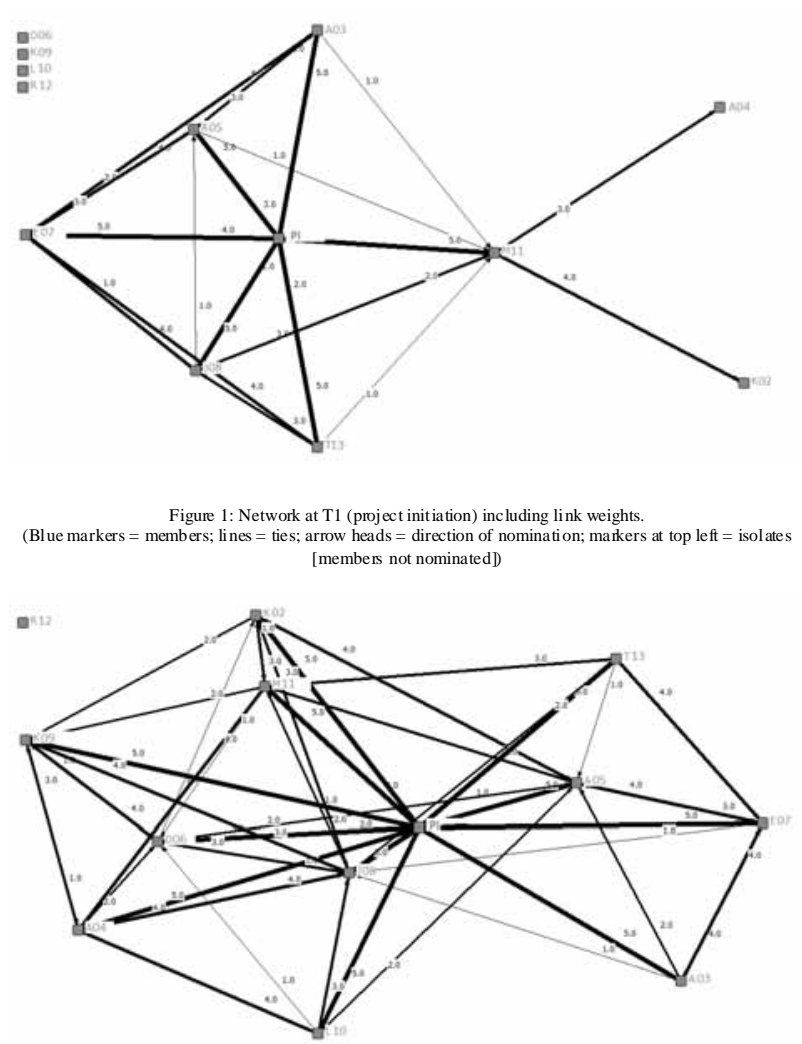

Figure 2: Net work at T2 (planning completion, start of implement ati on) including link weights (Blue markers = members; lines = ties; arrow heads $=$ direction of nomination; marker at top left $=$ isolate

centrality for several members, and one member (member J08) assumed a knowledge leadership role (with an in-degree centrality score of 25.00) second only to the PI/project champion. Standard deviation of the scores at $\mathrm{T} 2$ nearly doubled as a greater number of individuals became more central while network centralization increased. At T1, the most central actors were academic stakeholders who were critical in the initial proposal of the project. However, by T2 academic stakeholders other than the PI/project champion have decreased significantly in their centrality scores as community stakeholders are increasingly seen as leading the project. It is notable that at T1 the school principals at the two participating elementary schools both received nominations even though they were not yet directly involved in the project. This is because they were seen as natural opinion leaders for school-based interventions. This is born out at T2 by the fact that one of the school principals became more central as the project developed (increasing from inDC $=3.00$ to inDC=21.00) while the other, who in the interim stepped down as principal to return to classroom teaching, maintained the same centrality score (inDC=4.00).

At $\mathrm{T} 2$ the network grew in size as new members and organisations were recruited following the initial team discussions that took place at T1. For the purpose of analysis these members are considered part of the network at $\mathrm{T} 1$, but generated no data because they would not have nominated any actors as they had not yet begun to participate in the project. However, treating the network as a cohort across these two times, as well as for future samples, will allow for further analysis later in the project (to be discussed below).

\section{Discussion}

As expected, the PI/project champion was the central figure in the knowledge network during these two stages of the project. Although the stakeholder committee was well developed and functional, it still required the regular leadership of the original project champion. However, over the course of the project, community members became increasingly engaged, as is measured by their increase in centrality. Once the committee 
had functioned for over a year to achieve its goals, the knowledge and competence concerning the project had spread among the stakeholders, with other central figures emerging. In particular, one KSDPP staff member who was responsible for organising the stakeholder meetings became more central. At the same time, several individuals who were central at the outset of the project (T1) played a reduced role at T2 and were perceived to have proportionately less influence over the project. This is particularly true for the university-based academic participants (other than the PI/champion), even one who was originally from the community and was involved early on in the project but then left the community for another academic appointment and was no longer involved in its regular operation.

During the course of the project, the PI/champion's goal was to spread the work and the decision making among the stakeholders, to some success. However, the committee still relied on the direction of the project champion. Nevertheless, with the emergence at $\mathrm{T} 2$ of other more central members, the network can be seen to be transitioning from a highly centralised one towards a network containing new knowledge leadership, a base on which to function once the original project leader steps down at T3, although its sustainability is only hypothesised at this point. By that time, it is expected that the continued trend may produce one or more new central champions, with other members occupying supporting knowledge roles within the network. The effectiveness of the new network structure for sharing and applying knowledge for successful intervention may depend on the overall network centralisation at that time, as knowledge-leaders are more influential in centralised networks (Valente, 2010).

Implications for community ownership and self-determination: Selfdetermination, the ability of individuals or groups to determine their own future, has been a central topic in health research - particularly public health research, since the 1980s as vulnerable or marginalised populations have attempted to take control over their own health and the evidence that informs the interventions, policies and programs that address it. This has been most evident among Indigenous and minority groups (T. Young, Kue, 1994; T. K. Young, Reading, Elias, \& O’Neil, 2000), low socioeconomic status populations (Labonte, 1986; Robertson \& Minkler, 1994) and other underserved segments of society. Cargo and Mercer (M. Cargo \& Mercer, 2008) identified self-determination, alongside knowledge translation and social justice as the principal goals or values that drive participatory research and lead researchers to take a community-partnered approach to knowledge creation. Although the particular participatory processes that foster each of these three drivers have been explored, least is understood about the processes undertaken to achieve self-determination. Much has been written about the strategies for overall stakeholder engagement (Hermann et al., 2004; Kizer, 2001; Salsberg et al., 2015), particularly with communities (Israel, Schulz, Parker, \& Becker, 1998;A. Macaulay et al., 1998; Minkler \& Wallerstein, 2008). And the strategies and processes for knowledge translation, both in public policy and for health practice have been well described(Graham \& Tetroe, 2007; Parry, Salsberg, \& Macaulay, 2009; Salsberg, Macaulay, \& Parry, 2014). Participatory strategies that directly attempt to build ownership and self-determination are less well described and rarely if ever evaluated. Even where ownership has been evaluated (M. Cargo, et al., 2011; M Cargo, et al., 2003), it was as an outcome measure of overall 'participation' by community members, with no exploration of individual measures within the participatory process that intentionally targeted self-determination.

Examining how influence and knowledge sharing shifts among organisations engaged in school-based PA intervention demonstrates how specific individuals or organisations take the lead as the project evolves. Results describe the emergence of new knowledge leaders, and the change in network centralisation within which the knowledge leaders function. Community ownership grew as the project developed and community members took on more central roles while university-based stakeholders were perceived to be of less influence. This emergent ownership can be seen as an assertion of community self-determination over the project. Furthermore, a direct line can be drawn from the recruitment of community members to the project, to their active engagement and finally the emergent community ownership over the project. This trajectory sheds light on how self-determination evolves as the influence of key actors changes over time. Ahypothetical network reflecting full community ownership and self-determination would have community knowledge leaders in central positions, with non-community stakeholders either absent or in positions of lower influence. The actual network is moving in that direction, but only future sampling will show if this trend is sustained.

These findings have implications for designing participatory processes that work to democratise the governance of communityuniversity-partnered research project. PA intervention planning, though predicated on strong community ownership and inter-organisational collaboration, can nonetheless require academic attention particularly in its early stages, in order to foster this ownership.

\section{Limitations}

There are many environmental influences on both the building of community ownership and the successful implementation of schoolbased PAinterventions; social relationship is but one, albeit one that has received growing attention. By focussing on inter-stakeholder relations, we are not examining other aspects such as historical context, resource availability, encompassing physical and political environments, or other important factors. However, understanding the social dynamics can serve as a basis for later examination of how these other influences are accessed and applied within a multi-stakeholder community setting. Using the current data it is impossible to state the reason for the shift in network structure toward community ownership. To explain this shift, further samples will be needed at future key time points, as well as a qualitative exploration of stakeholders' experiences. Finally, because this is a whole-network sample based on egocentric data, results may not be generalizable to network evolution in other settings. However, using this as a case study illuminates how a stakeholder network may evolve under similar contextual circumstances and under the influence of similar participatory strategies. It may therefore be useful to others as a guide for designing participatory intervention processes within their own projects.

\section{Conclusion and further direction for research}

This study set out to examine how a network of community and university stakeholders engaged in developing and deploying a schoolbased PA intervention changed over time. By looking at how the idea was initiated by an extra-community champion (whose goal was to support community capacity development), then community members and organisations were recruited, engaged and actively given the opportunity to take the lead, we hope we have increased our understanding of how community ownership an self-determination are grown. As stated, this has particular importance for community-based participatory intervention projects that are initiated by academics, but which must develop community ownership in order to be sustained (Cacari-Stone, et al., 2014).

As stated in the limitations, further study will attempt to explain the shifts in network influence described in the current data. Network data collected once the non-community PI removes herself from the project (T3), and again once the STP-Committee has run the intervention repeatedly in the PI's absence (T4) will provide enough data to do a longitudinal network analysis using exponential random graph models to demonstrate the significance of change. Furthermore, qualitative interviews underway with members of the STP-Committee will explore the link between what occurred during the course of the STP project, including the use of participatory strategies to intentionally shift control to the community, and the observed shifts in network influence. This latter phase will draw together the results of the current and proposed network analyses to develop a clearer picture of how and why community self-determination emerges in participatory health intervention research. 


\section{Acknowledgements}

This study was supported by the Kahnawake Schools Diabetes Prevention Project (KSDPP), and both the study and this manuscript have been reviewed and approved by its Community Advisory Board. The study could not have taken place without the hard work of the KSDPP STP-Committee, including Kanahsohon Deer, Kwawenna:wi Diabo-Alfred, Arlene Goodleaf, Judi Jacobs, Morrison King, Dennis Leborgne, and Soultana Macridis, in their dedication to develop an active transportation program for two of Kahnawake's elementary schools. Jon Salsberg was supported by a Frederick Banting and Charles Best Canada Graduate Scholarships Doctoral Award from the Canadian Institutes of Health Research (CIHR). Soultana Macridis was supported by a CIHR Network Environment for Aboriginal Health Research (AK-NEAHR) Doctoral Award. Spencer Moore holds a New Investigator's Award from the CIHR Institute of Aging.

\section{References}

Active-Healthy-Kids-Canada. (2014). Is Canada in the running? How does Canada stackup against 14 other countries on physical activity for children and youth? Toronto: Active Healthy Kids Canada.

Bisset, S.A., Daniel, M., \& Potvin, L. (2009). Exploring the InterventionContext Interface: A Case from a School-Based Nutrition Intervention. . American Journal of Evaluation, 30(4), 554-571.

Buliung, R., Faulkner, G., Beesley, T., \& Kennedy, J. (2011). School travel planning: mobilizing school and community resources to encourage active school transportation. The Journal of school health, 81(11), 704-712.

Cacari-Stone, L., Wallerstein, N., Garcia, A. P., \& Minkler, M. (2014). The promise of community-based participatory research for health equity: a conceptual model for bridging evidence with policy. [Research Support, Non-U.S. Gov't]. American journal of public health, 104(9), 1615-1623.

Campbell, N., Schiffer, E., Buxbaum, A., McLean, E., Perry, C., \& Sullivan, T. M. (2014). Taking knowledge for health the extra mile: participatory evaluation of a mobile phone intervention for community health workers in Malawi. Glob Health Sci Pract, 2(1), 23-34.

Cargo, M., \& Mercer, S. L. (2008). The value and challenges of participatory research: strengthening its practice. Annu Rev Public Health, 29, 325-350.

Cargo, M., Delormier, T., Levesque, L., McComber, A., \& Macaulay, A. (2011). Community capacity as an «inside job»: Evolution of perceived ownership of a university-Aboriginal community partnership. American Journal of Health Promotion, 26(2), 96100.

Cargo, M., Levesque, L., Macaulay, A., McComber, A., Desrosiers, S., Delormier, T., et al. (2003). Community Governance of the Kahnawake Schools Diabetes Prevention Project, Kahnawake Territory, Mohawk Nation, Canada. Health Promotion International, 18(3), 177-187.

Chillon, P., Evenson, K. R., Vaughn, A., \& Ward, D. S. (2011). A systematic review of interventions for promoting active transportation to school. The international journal of behavioral nutrition and physical activity, 8, 10.

Costenbader, E., \& Valente, T. W. (2003). The stability of centrality measures when networks are sampled. Social Networks, 25(4), 283-307.

Doak, C. M., Visscher, T. L., Renders, C. M., \& Seidell, J. C. (2006). The prevention of overweight and obesity in children and adolescents: a review of interventions and programmes. [Review]. Obesity reviews : an official journal of the International Association for the Study of Obesity, 7(1), 111-136.

Eccles, M., \& Foy, R. (2011). Linkage and exchange interventions. In S, Strauss, J.Tetroe \& I. D. Graham (Eds.), Knowledge Translation in Health Care: Moving From Evidence to Practice (1rst ed.): WileyBMJ Books.
Fuller, J., Hermeston, W., Passey, M., Fallon, T., \& Muyambi, K. (2012). Acceptability of participatory social network analysis for problem-solving in Australian Aboriginal health service partnerships. BMC Health Serv Res, 12, 152.

Galaskiewicz, T. (1979). The Structure of Community Organizational Networks. Social Forces, 57(4), 1346-1364.

Gest, S. D., Osgood, D.W., Feinberg, M. E., Bierman, K. L., \& Moody, J. (2011). Strengthening prevention program theories and evaluations: contributions from social network analysis. Prev Sci, 12(4), 349-360.

Graham, I. D., \& Tetroe, J. (2007). How to translate health research knowledge into effective healthcare action. Healthcare Quarterly, 10(3), 20-22.

Green, L. W., \& Kreuter, M. W. (2005). Health program planning : an educational and ecological approach (4thed.). New York: McGrawHill.

Green-Communities Canada. (2012). Canadian School Travel Planning Facilitator Guide, $h t t p: / / w w w . s a f e r o u t e s t o s c h o o l . c a$.Toronto: GreenCommunities-Canada.

Hermann, R. C., Palmer, H., Leff, S., Shwartz, M., Provost, S., Chan, J., et al. (2004). Achieving Consensus Across Diverse Stakeholders on Quality Measures for Mental Healthcare. Medical Care, 42(12), 1246-1253.

Hogan, L., Bengoechea, E. G, Salsberg, J., Jacobs, J., King, M., \& Macaulay, A. C. (2014). Using a participatory approach to the development of a school-based physical activity policy in an indigenous community. The Journal of school health, 84(12), 786792.

Israel, B.A., Schulz,A. J., Parker, E. A., \& Becker, A. B. (1998). Review of community-based research: assessing partnership approaches to improve public health. Annual Review of Public Health, 19, 173202.

Kegler, M. C., Rigler, J., \& Ravani, M. K. (2010). Using network analysis to assess the evolution of organizational collaboration in response to a major environmental health threat. .Health Educ Res, 25(3), 413-424.

Kizer, K. W. (2001). EStablishing health care performance standards in an era of consumerism. JAMA, 286(10), 1213-1217.

Labonte, R. (1986). Social inequality and healthy public policy. Health Promotion, 1(3), 341-351.

Langhout, R. D., Collins, C., \& Ellison, E. R. (2013). Examining relational empowerment for elementary school students in a yPAR program. Am J Community Psychol, 53(3-4), 369-381.

Leonard, R., Horsfall, D., \& Noonan, K. (2014). Identifying changes in the support networks of end-of-life carers using social network analysis. BMJ Support Palliat Care.

Luke, D. A., \& Harris, J. K. (2007a). Network analysis in public health: history, methods, and applications. Annu Rev Public Health, 28, 69-93.

Luke, D. A., \& Harris, J. K. (2007b). Network analysis in public health: history, methods, and applications. [Review]. Annual review of public health, 28, 69-93.

Luque, J. S., Tyson, D. M., Bynum, S. A., Noel-Thomas, S., Wells, K. J., Vadaparampil, S. T., et al. (2011). A social network analysis approach to understand changes in a cancer disparities community partnership network. Ann Anthropol Pract, 35(2).

Macaulay AC, Ing A, Salsberg J, McGregor A, Arroz J, Montour L, et al. Compartir los resultados con la comunidad: investigación participativa basada en la comunidad. Un ejemplo de la traducción del conocimiento del Proyecto de Prevención de la Diabetes Kahnawake Escuelas. El progreso en Asociaciones de Salud Comunitaria: Investigación, Educación y Acción 2007; 1 (2): 143-152.

Macaulay, A. C., Commanda, L. E., Freeman, W. L., Gibson, N., McCabe, M. L., Robbins, C. M., et al. (1999). Participatory research maximises community and lay involvement. North American Primary Care Research Group. BMJ, 319(7212), 774-778. 
Macaulay, A. C., Paradis, G., Potvin, L., Cross, E. J., Saad-Haddad, C., McComber, A., et al. (1997). The Kahnawake Schools Diabetes Prevention Project: intervention, evaluation, and baseline results of a diabetes primary prevention program with a native community in Canada. Prev Med, 26(6), 779-790.

Macaulay, A., Delormier, T., Cross, E., Potvin, L., Paradis, G., Kirby, R., et al. (1998). Participatory research with the Native Community of Kahnawake creates innovative Code of Research Ethics. Can J Public Health, 89, 105 - 108.

Macridis, S, Garcia Bengoechea, E. 2015. Adoption of Safe Routes to School in Canadian and the United States Contexts - Best Practices and Recommendations. Journal of School Health. Manuscript ID: JOSH-07-14-JA-255.R1. (in press)

Macridis, S. 2015. An Ethnographic Evaluation of a CommunityBased Participatory Research Project: Understanding Community Mobilization \& Participation in School Active Transportation Initiatives in the Kanien'kehá:ka Community of Kahnawake, Quebec. Unpublished Doctoral Thesis, Department of Kinesiology \& Physical Education in the Faculty of Education, McGill University, Montreal, Canada

Minkler, M., \& Wallerstein, N. (2008). Community-based participatory research for health : from process to outcomes (2nd ed.). San Francisco: Jossey-Bass.

Paradis, G., Levesque, L., Macaulay, A. C., Cargo, M., McComber, A., Kirby, R., et al. (2005). Impact of a diabetes prevention program on body size, physical activity, and diet among Kanien'keha:ka (Mohawk) children 6 to 11 years old: 8-year results from the Kahnawake Schools Diabetes Prevention Project. Pediatrics, 115(2), 333-339.

Parry, D., Salsberg, J., \& Macaulay, A. C. (2009). A Guide to Researcher and Knowledge-User Collaboration in Health Research. http:// www.cihr-irsc.gc.ca/e/44954.html. Last Accessed: 26 March, 2015. Ottawa: Canadian Institutes of Health Research.

Pauly, B. B., MacDonald, M., Hancock, T., Martin, W., \& Perkin, K. (2013). Reducing health inequities: the contribution of core public health services in BC. BMC Public Health, 13, 550 .

Poole, D. (2008). Organizational Networks of Collaboration for Community-Based Living. Nonprofit Management \& Leadership, 18(3), 275-293.

Potvin, L., \& Lamarre, M. C. (2009). [Coordination between national and local initiatives in order to strengthen health promotion]. Global health promotion, 16(4), 75-82.

Provan, K. G., Nakama, L., Veazie, M. A., Teufel-Shone, N. I., \& Huddleston, C. (2003). Building community capacity around chronic disease services through a collaborative interorganizational network. Health Educ Behav, 30(6), 646-662.

Ramanadhan, S., Salhi, C., Achille, E., Baril, N., D’Entremont, K., Grullon, M., et al. (2012). Addressing cancer disparities via community network mobilization and intersectoral partnerships: a social network analysis. PLoS One, 7(2), e32130.
Richard, L., Potvin, L., Kishchuk, N., Prlic, H., \& Green, L. W. (1996). Assessment of the integration of the ecological approach in health promotion. American Journal of Health Promotion, 10(4), 318328.

Robertson,A., \& Minkler, M.(1994). New health promotion movement: a critical examination. Health Educ Q, 21(3), 295-312.

Rogers, E. M. (2003). Diffusion of innovations (5th ed.). New York: Free Press.

Salsberg, J., Macaulay, A. C., \& Parry, D. (2014). Guide to Integrated Knowledge Translation Research. In I. D. Graham, J. Tetroe \& A. Pearson (Eds.), Integrated Knowledge Translation Research: Turning Knowledge Into Action (2nd ed., pp. 176-182). Adelaide: Lippincott-Joanna Briggs Institute.

Salsberg, J., Parry, D., Pluye, P., Macridis, S., Herbert, C., \& Macaulay, A. C. (2015). Practical Strategies For Successfully Translating Evidence Into Action In Community Health: A Critical Review. Journal of Environmental and Public Health (in revisions).

Shin, H. S., Valente, T. W., Riggs, N. R., Huh, J., Spruijt-Metz, D., Chou, C. P., et al. (2014). The interaction of social networks and child obesity prevention program effects: the pathways trial. Obesity (Silver Spring), 22(6), 1520-1526.

Story, M., Kaphingst, K. M., \& French, S. (2006). The role of schools in obesity prevention. The Future of children / Center for the Future of Children, the David and Lucile Packard Foundation, 16(1), 109-142.

Turcot, V., Rouleau, T., Tsopmo, A., Germain, N., Potvin, L., Nuyt, A. M., et al. (2009). Long-term impact of an antioxidant-deficient neonatal diet on lipid and glucose metabolism. [Research Support, Non-U.S. Gov't]. Free radical biology \& medicine, 47(3), 275282.

Valente, T. W. (2010). Social networks and health : models, methods, and applications. Oxford ; New York: Oxford University Press.

Valente, T. W., Coronges, K. A., Stevens, G. D., \& Cousineau, M. R. (2008). Collaboration and competition in a children's health initiative coalition: a network analysis. Eval Program Plann, 31(4), 392402.

Valente, T. W., Fujimoto, K., Palmer, P., \& Tanjasiri, S. P. (2010). A network assessment of community-based participatory research: linking communities and universities to reduce cancer disparities. Am J Public Health, 100(7), 1319-1325.

Veugelers, P. J., \& Fitzgerald, A. L. (2005). Effectiveness of school programs in preventing childhood obesity: a multilevel comparison. Am J Public Health, 95(3), 432-435.

Young, T. K., Reading, J., Elias, B., \& O’Neil, J. D. (2000). Type 2 diabetes mellitus in Canada's first nations: status of an epidemic in progress. CMAJ Canadian Medical Association Journal, 163(5), 561-566.

Young, T., Kue. (1994). The Health of Native Americans : Toward a Biocultural Epidemiology. New York: Oxford University Press.

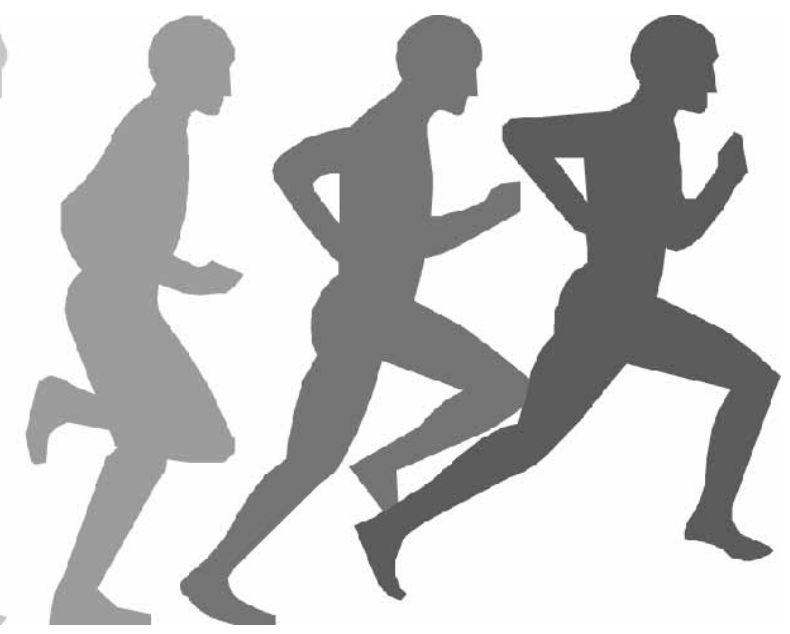

